\title{
Hybrid sandwich panels for building uses: focus on glass fibre reinforced polymer and mineral matrix interface.
}

\author{
Khaled Djama*, Laurent Michel, Emmanuel Ferrier, and Aron Gabor
}

Université de Lyon, Université Lyon 1, Laboratory of Composite Materials for Construction (LMC2), 82 bd Niels Bohr, 69622 Villeurbanne Cedex, France

\begin{abstract}
Sandwich structures are being used increasingly in civil engineering because of their high strength, stiffness, and stiffness-to-density ratio. The studied sandwich structure was made of glass fibre reinforced polymer (GFRP) skins, and GFRP reinforced core. Two case studies are presented in this paper: a use as lightweight floor in building rehabilitation, and an application as façade panels. In both cases, the GFRP sandwich structure can be associated with a mineral matrix because of conventional construction methods and acoustic floor insulation in the first case, and because of architectural issues in the second. To design the hybrid sandwich panel and ensure monolithic mechanical behaviour, a finite element method (FEM) that predicts the interface failure was introduced. To implement the FE model by mechanical interface properties, pull-off and push-out tests were performed to assess the mode I and mode II stress limits. Four GFRP surface roughnesses and two configurations with chemical additions were tested. The three configurations that performed the best were tested by submitting the hybrid sandwich structure to three-point bending loading. The prediction of the interface failure by the FEM was assessed by comparison to the experimental data. Finally, full-scale panels were experimentally tested and designed for the named two uses cases thanks to the FE model.
\end{abstract}

\section{Introduction}

Sandwich panels were introduced during World War II [1] to ensure high mechanical performance using low-weight structures. The demand for low-weight structures was high in the warplane sector. Nowadays, this high stiffnessto-weight ratio requirement remains valid in several industrial sectors [2] like civil aerospace, automobiles, rail cars, etc. In civil engineering, numerous applications can be found. Chróścielewski et al. [3] presented a sandwich footbridge in 2017. The full-scale structure was subjected to static load under real climatic conditions. Cementitious materials are omnipresent in civil engineering sandwich panels, for their mechanical properties, fire resistance, and construction patterns. Hopkins et al. [4] investigated the creep behaviour of concrete roof and floor sandwich panels. Other applications as façade panels can be cited. Sharaf and Fam [5] analysed the bending behaviour of large-scale ( $9145 \times$ $2440 \times 78 \mathrm{~mm}$ ) cladding sandwich panels, simply supported at six points. Pascual et al. [6] emphasised the physical feasibility of fabricating composite sandwich structures by bonding glass face sheets to GFRP core profiles.

Conventional sandwich panels are composed of thin stiff skins and a low-density core. Generally, the cores are made of polyurethane, polystyrene, aluminium, or concrete foams. The skins could be metallic, mineral, or composite. Structural issues of conventional sandwich panels were well studied in the last decades. Mainly, the low mechanical properties of foams lead to high shear deflection and shear failure, and small skin thicknesses caused buckling under compression load. To address these issues, the introduction of metallic and composite connectors and ribs in conventional cores was investigated and presented in several articles [7-9]. Numerous enhancements, which are centred on the idea of increasing the core stiffness while maintaining a low density, have been proposed in the so-called unconventional core. Currently, the widely used unconventional core is known as a cell-designed core. It includes honeycomb, re-entrant honeycomb, auxeticstrut, and auxetic honeycomb core structures [2]. The use of truss core sandwich structures significantly increased during the last decade because of major advances in cutting and three-dimensional printing processes [10-12]. Five types of truss cores can be outlined [2]: corrugated, pyramidal truss, tetrahedral truss, Xtype truss, and Kagome truss cores.

$\mathrm{Be}$ that as it may, sandwich panels are multi-layered structures. Because of the different mechanical properties between adjacent layers, stress concentrations at the interface appear, making the panel subject to interface failure. Many authors have addressed this issue: Mitra et al. [13] assessed the interfacial delamination of a polymer foam-cored sandwich composites through peeling tests; Pietrek and Horst [15] proposed a finite element model that correctly reproduced the skin delamination and the buckling behaviour of an asymmetric sandwich panel. In brief, implementation and validation of models that can

Corresponding author: khaled.djama@univ-lyon1.fr. 

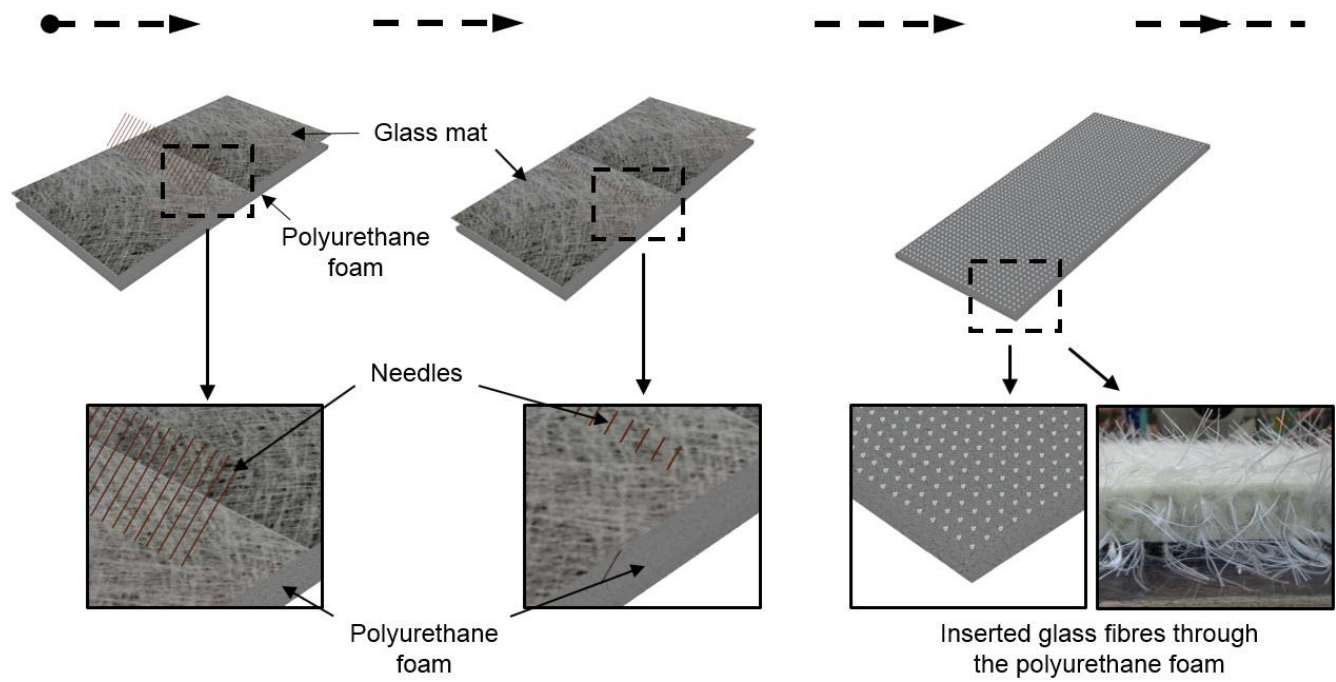

Fig. 1. First stage of the manufacturing process: Glass fibres are inserted through polyurethane foam [14].

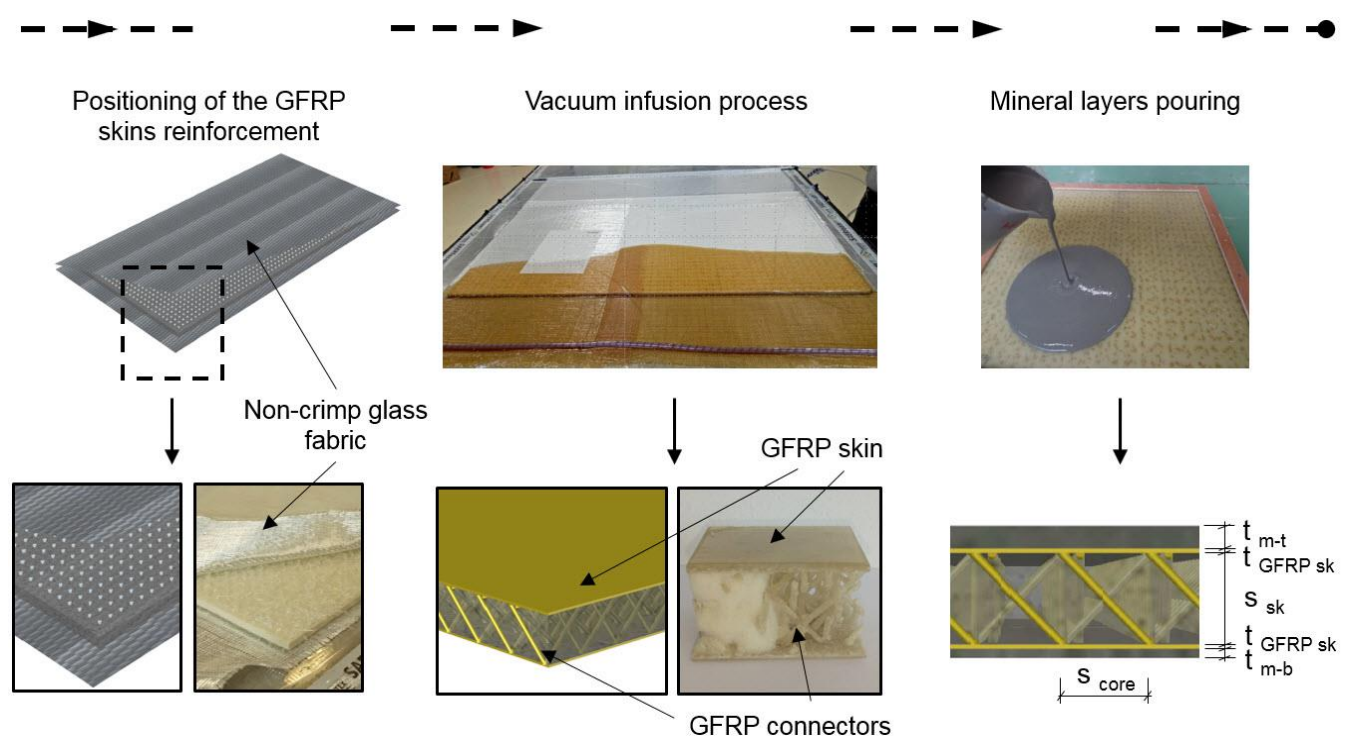

Fig. 2. Second stage of the manufacturing process: Sandwich panel fabrication [14].

well predict the interface delamination is a vital issue in the design procedure.

This study investigated the mechanical properties of the mineral-GFRP interface of hybrid skins, which were connected by GFRP-strengthened polyurethane foam. The truss core was fabricated by a novel patented manufacturing method [16] detailed in the following section. In this work, the mechanical properties of the interface were first assessed through an experimental campaign. Six different interfaces were tested. Then, a finite element model was implemented to predict the interface failure thanks to surface-based cohesive analysis [17]. The simulation responses were compared to experimental responses of three-point bending tests. The use of the presented panel in the field of building refurbishment was assessed through two applications: cladding panels and lightweight floor panels.

\section{Manufacturing and materials properties}

The studied sandwich structure was made of hybrid mineral-GFRP skins and polyurethane foam. The skins were connected by GFRP connectors that crossed the polyurethane foam. In the manufacturing process, $20 \mathrm{~mm}$ spaced needles crossed, numerous times, a stretched glass mat fabric and the polyurethane foam, in order to insert connecting glass fibre reinforcement (cf. Fig. 1). Then, the GFRP skin's reinforcement was positioned (non-crimp glass fabric $\left[0^{\circ} / 90^{\circ}\right]$ ), and a vacuum infusion of an epoxy matrix was performed. Finally, the top and bottom mineral layers were poured (cf. Fig. 2). Fig. 3 presents the truss core geometry. The section parameters are presented in Table 1, and the geometric parameters of the truss core are given in Table 2. 


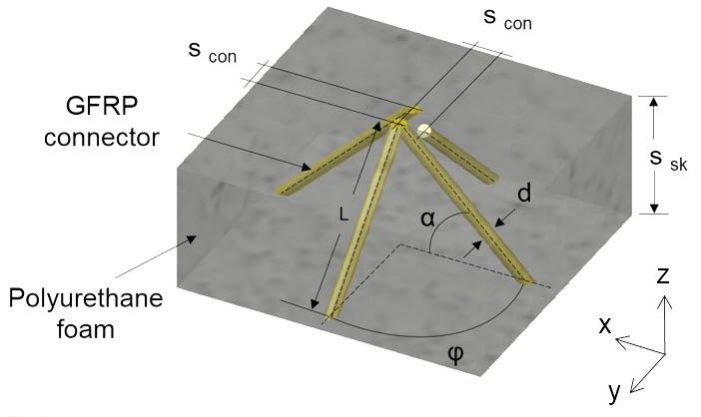

(a)

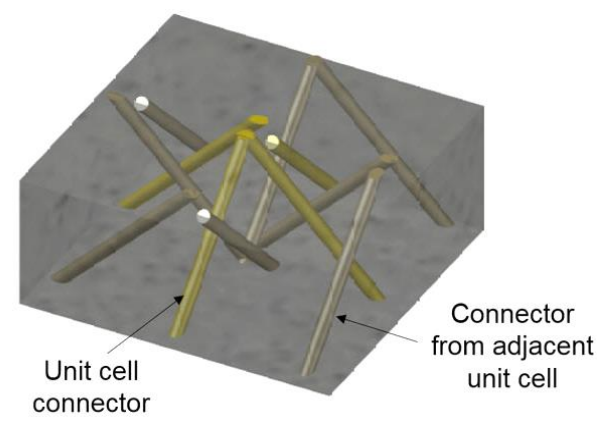

(b)

Fig. 3. Truss core geometry: (a) relevant parameters of the truss core unit cell; (b) complete unit cell: core unit cell with connectors from adjacent truss core unit cells [14].

Table 1. Cross-section parameters.

\begin{tabular}{ll}
\hline Parameter & Value $(\mathrm{mm})$ \\
\hline $\mathrm{t}_{\mathrm{m}-\mathrm{t}}$ : thickness of the top mineral layer & 5 \\
$\mathrm{t}$ GFRP sk: thickness of the GFRP skins & 1 \\
$\mathrm{~S}$ sk: spacing between skins & 20 \\
$\mathrm{t}_{\text {b-t: }}$ thickness of the bottom mineral layer & 2 \\
$\begin{array}{l}\mathrm{S} \text { core: spacing between truss core unit cells } \\
\text { (between connector's nodes) }\end{array}$ & 20 \\
\hline
\end{tabular}

Table 2. Truss core geometric parameters.

\begin{tabular}{ll}
\hline Parameter & Value \\
\hline $\mathrm{S}$ sk: skins spacing & $20 \mathrm{~mm}$ \\
$\mathrm{~S}$ con: connector spacing & $5 \mathrm{~mm}$ \\
$\mathrm{~L}:$ connector length & $28 \mathrm{~mm}$ \\
$\mathrm{~d}:$ connector diameter & $2 \mathrm{~mm}$ \\
$\alpha:$ connector inclination & $45^{\circ}$ \\
$\varphi:$ connector orientation & $90^{\circ}$ \\
\hline
\end{tabular}

The mechanical properties of the panel's components were determined through various tensile and compression tests. The assessed components were the mineral layer, the GFRP skins, and the GFRP connectors. Table 3 summarized the extracted mechanical parameters.
Table 3. Mechanical properties of panel's components.

\begin{tabular}{llll}
\hline Material & Test & Parameter & Value (MPa) \\
\hline Mineral layer & Compression [18] & E & $13269(4.7 \%)$ \\
& & $\sigma$ & $42.5(1.77 \%)$ \\
& & $0.4 \sigma$ & $17.3(0.69 \%)$ \\
& Tension [18] & E & $15700(1.62 \%)$ \\
GFRP skins & NF EN 527 & E & $4.5(6.19 \%)$ \\
& & $\sigma$ & $137.8(19.04 \%)$ \\
$\begin{array}{l}\text { GFRP } \\
\text { connectors }\end{array}$ & Compression & E & $1593(5.6 \%)$ \\
$\begin{array}{l}\text { Polyurethane } \\
\text { foam }\end{array}$ & NF EN 826 & E & $2331(11.6 \%)$ \\
$*$ manufacturer value & E & $1.8 *$ \\
\hline
\end{tabular}

\section{Interface characterisation}

The mechanical properties of six interfaces were investigated through tensile and push-out tests. Fig. 4 presents the tested interfaces. Interface (a) is the reference that has been obtained simply by removing peel-ply fabric after the vacuum infusion $\left(R_{a}^{(a)}=23.26 \mu \mathrm{m} ; R_{q}^{(a)}=\right.$ $29.79 \mu \mathrm{m}$ ). Interfaces (b), (c) and (d) had different roughnesses. Interface (b) and (c) were obtained by using different peel-ply fabrics $\left(R_{a}^{(b)}=94.63 \mu \mathrm{m} ; R_{q}^{(b)}=\right.$ $\left.117.61 \mu \mathrm{m} ; R_{a}^{(c)}=111.66 \mu \mathrm{m} ; R_{q}^{(c)}=138.63 \mu \mathrm{m}\right)$. Interface (d) was composed of interleaf sand layer between the reference interface and the mineral layer $\left(R_{a}^{(d)}=148.84 \mu m ; \quad R_{q}^{(d)}=189.38 \mu m\right) . \quad$ The manufacturing steps that lead to this interface are detailed in Fig. 5. The sand sieving properties and its chemical composition are presented in Table 4 . In interface (e), an adhesive primer was applied on the reference interface before the mineral layer pouring. In interface (f), an adhesive powder was mixed to the mineral one.

Table 4. Sand characteristics.

\begin{tabular}{llll}
\hline Sieve $(\mu \mathrm{m})$ & Passing $(\%)$ & \multicolumn{2}{c}{ Composition } \\
\hline 630 & 99.9 & $\mathrm{SiO}_{2}$ & $98.4 \%$ \\
500 & 98.7 & $\mathrm{Fe}_{2} \mathrm{O}_{3}$ & $0.021 \%$ \\
400 & 90.7 & $\mathrm{Al}_{2} \mathrm{O}_{3}$ & $0.848 \%$ \\
315 & 64.2 & $\mathrm{TiO}_{2}$ & $0.024 \%$ \\
250 & 30.6 & $\mathrm{CaO}$ & $0.008 \%$ \\
200 & 11.8 & $\mathrm{~K}_{2} \mathrm{O}$ & $0.493 \%$ \\
160 & 3.8 & & \\
125 & 1.1 & & \\
100 & 0.4 & & \\
0 & 0 & & \\
\hline
\end{tabular}




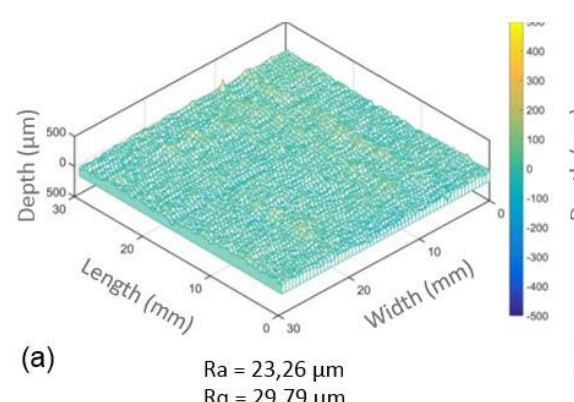

$\mathrm{Rq}=29,79 \mu \mathrm{m}$

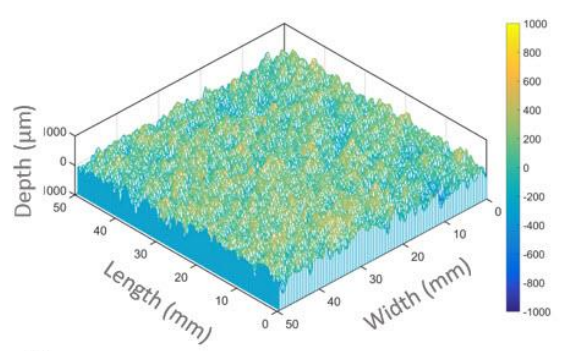

(d)

$\mathrm{Ra}=148,84 \mu \mathrm{m}$

$\mathrm{Rq}=189,38 \mu \mathrm{m}$

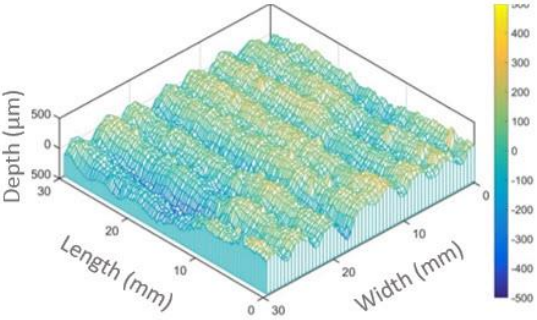

(b)

$$
\mathrm{Ra}=94,63 \mu \mathrm{m}
$$

$\mathrm{Rq}=117,61 \mu \mathrm{m}$

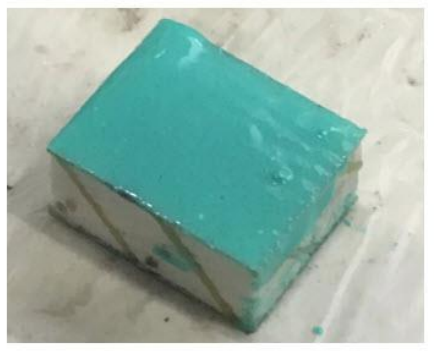

(e)
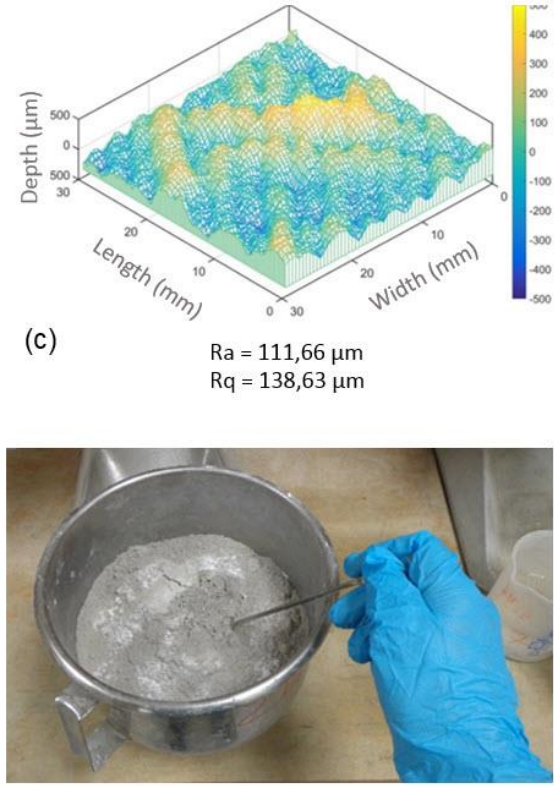

(f)

Fig. 4. Tested interfaces: (a) reference interface; (b) and (c) use of different peel-ply to increase the roughness; (d) interleaf sand layer (cf. Fig. 5); (e) adhesive primer; (d) addition of $0.05 \%$ of polyvinyl alcohol.

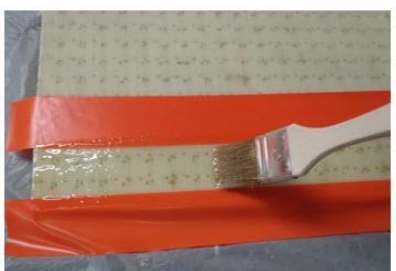

(a)

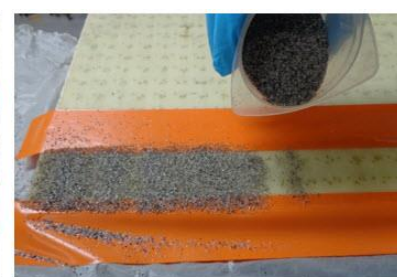

(b)

Fig. 5. Manufacturing steps of interface (d): (a) epoxy resin application. (b) sand pouring.

The additive was $0.05 \%$ of polyvinyl alcohol. This has a good interfacial bonding strength with silicon dioxide $\mathrm{SiO}_{2}$. The interfaces' roughness was assessed by laser scanning.

\subsection{Mode I}

The interface strength of mode I was assessed by tensile tests (cf. Fig. 6). The sizes of the mineral layer and the GFRP sandwich were designed to enforce failure at the interface. For each interface configuration, five specimens were tested.

Fig. 7 presents the obtained results by means of average values and standard deviation. Even though the failure modes were validated, the errors in the mean values can be explained by planarity issues and other geometry imperfections. However, the strand deviation values were acceptable. The experimental results showed that interfaces (d) and (e) performed the best. As expected, comparison between interfaces (a), (b), (c) and (d) highlighted that the substrate's roughness improved the interface strength of mode I. Indeed, in addition to mechanical anchorage, the increase of the roughness increased the contact area between the substrate and the

poured mineral layer. The chemical bond was therefore enhanced. The good strength of interface (e) was due to the improvement of the substrate wettability by the adhesive primer. In comparison with the reference interface, the addition of polyvinyl alcohol in interface (f) increased the strength of mode I, but not significantly in comparison with the other configurations.

\subsection{Mode II}

Mode II interface strength was assessed thanks to pushout tests (cf. Fig. 8). The specimens' sizes were designed to lead to interface failure. The free length of the mineral layer was $10 \mathrm{~mm}$. For each interface configuration, seven specimens were tested. Because of geometry imperfections, we registered inadequate failures as mineral layer fracture or GFRP skins buckling, numerous times. In this case, the results were cancelled.

The results of the push-out test presented in Fig. 9 were calculated from four specimen responses, at least. Although there were stress concentrations at the endpoints of the interface, the mode II interface strength was calculated as a uniform distribution of the applied force over the contact surfaces.

As for mode I, interfaces (d) and (e) performed the best. The substrate's roughness and its wettability are the key parameters to understand the results of push-out tests. In brief, the remarks made in the previous section for mode I are still valid to explain the experimental data of mode II. 


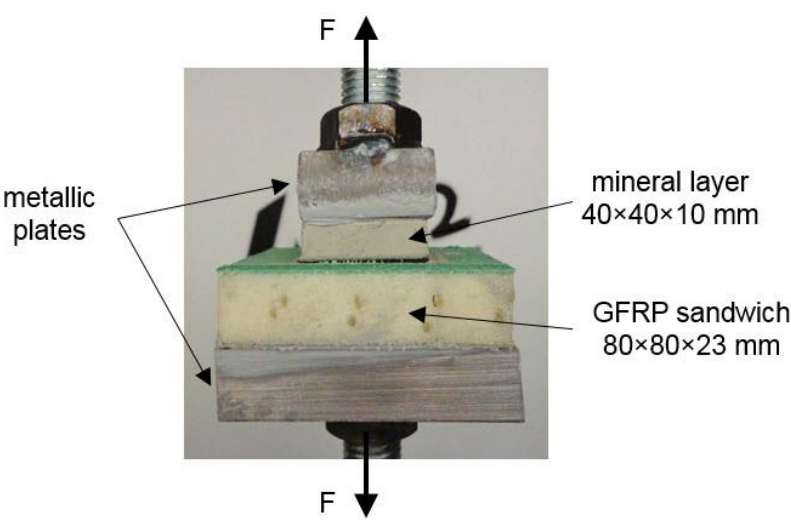

Fig. 6. Tensile test: interface strength of mode I.

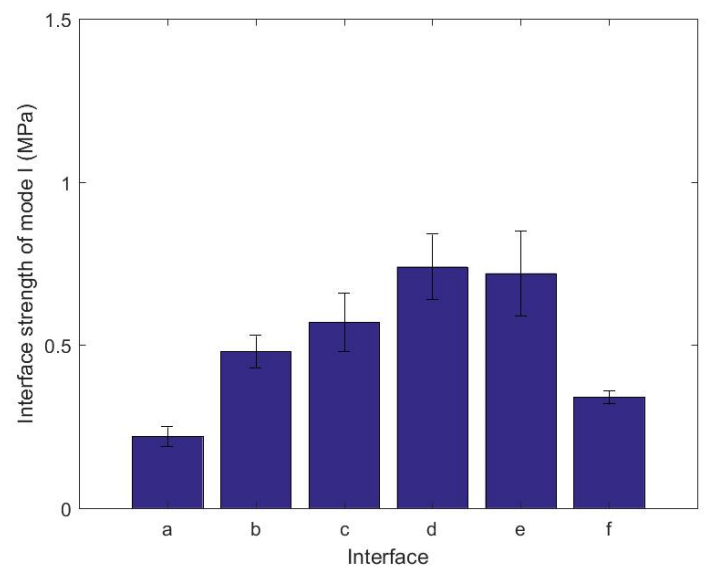

Fig. 7. Interface strength of mode I.

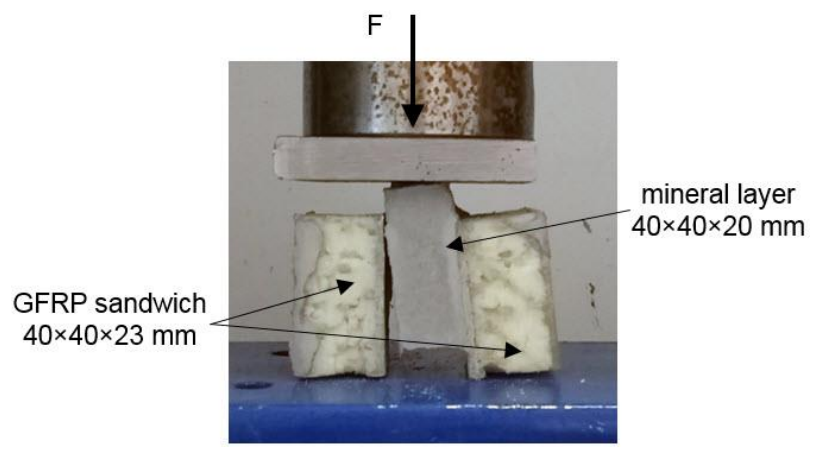

Fig. 8. Push-out test: interface strength of mode II.

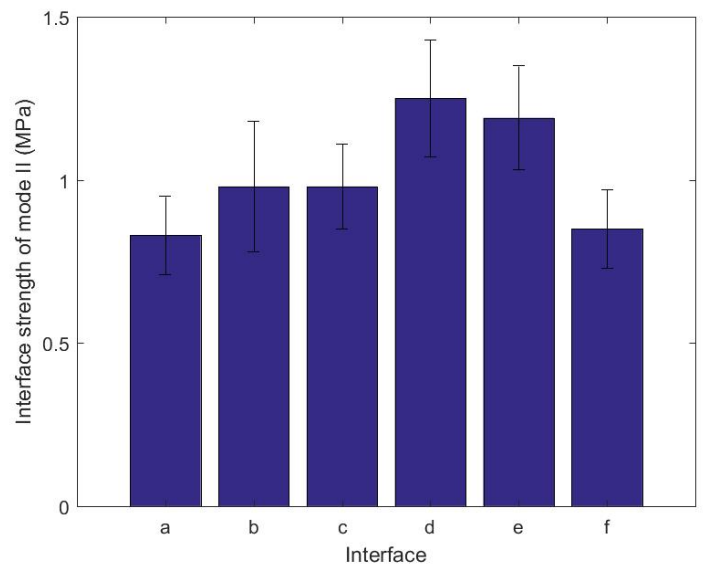

Fig. 9. Interface strength of mode II.

\section{Three-point bending test and FE modelling of interface behaviour}

The interface behaviour is modelled in this section. The purpose was to predict the interface failure using a finite element model implemented with the interfaces' strength that was previously assessed. To validate the model by comparison with experimental data, sandwich beams were tested under three-point bending load. The beam section fitted the one presented in Fig. 2 (the bottom layer of $2 \mathrm{~mm}$ thick was added to prevent fire issues). Two configurations were tested: configuration with interface (a) as a reference, and configuration with interface (d) that performed the best under tensile and push-out tests. Three specimens were tested for each configuration. The specimens' sizes were $90 \mathrm{~mm}$ width and $300 \mathrm{~mm}$ length. The test configuration was a short span one $(250 \mathrm{~mm})$, to enforce the interface failure. It was conducted at a displacement rate of $1 \mathrm{~mm} / \mathrm{min}$. The data acquisition of the applied force and the upper deflection was at a frequency of $2 \mathrm{~Hz}$.

The experimental results of the three-point bending test are presented in Fig. 11. The initial stiffness and the pre-peak behaviour are similar for the three tested configurations. The average initial stiffness, calculated between the deflection points of $0.4 \mathrm{~mm}$ and $0.8 \mathrm{~mm}$, was $912.7 \mathrm{~N} / \mathrm{mm}(6.14 \%)$. The forces at which the failure initiated are given in Table 5. The difference and similarity of the values are explained by the observed failure modes. As shown in Fig. 11, the failure mode of configuration (a) was mineral layer delamination, while the failure mode of configuration (d) was mineral layer multi-cracking and crushing. Therefore, the improvement of the interface mechanical properties changed the failure mode.

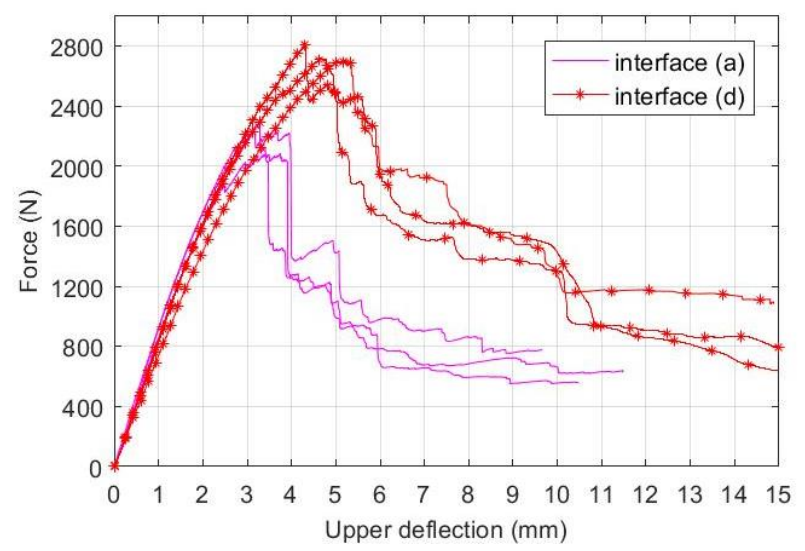

Fig. 10. Experimental results of the three-point bending test.

Table 5. Force at which the failure initiated.

\begin{tabular}{lll}
\hline Configuration & Interface (a) & Interface (d) \\
\hline Force $(\mathrm{N})$ & 2016 & 2733 \\
$\mathrm{CoV}(\%)$ & 6.10 & 1.97 \\
\hline
\end{tabular}




\section{Interface (a)}

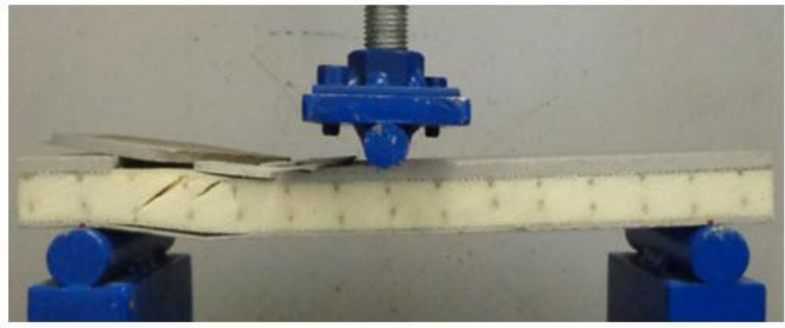

Interfaces (d)
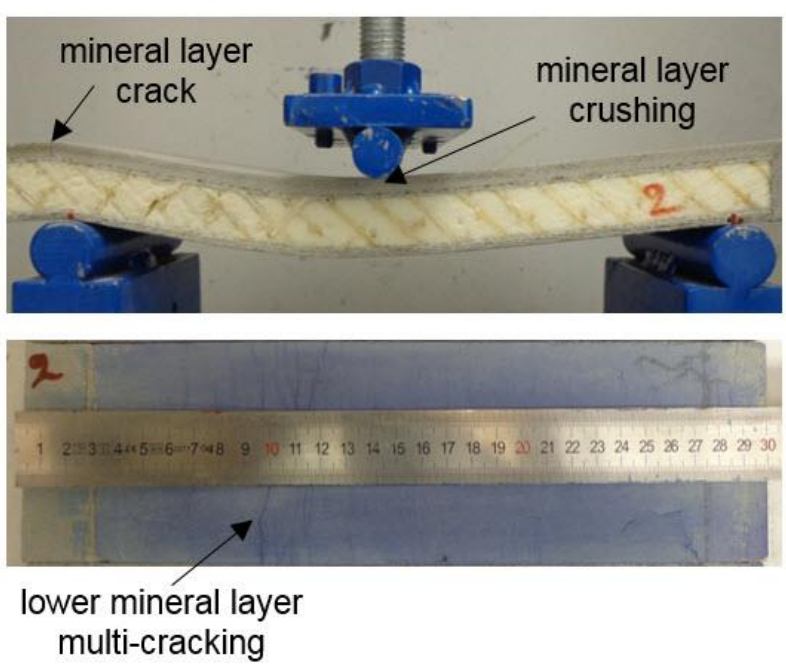

Fig. 11. Illustration of specimens' failure modes.

The FE model was implemented in Abaqus software [17]. The mineral layers were modelled with the Concrete Damage Plasticity (CDP) model [17, 19]. The retained material parameters are presented in Table 3 and Table 6. Hexahedral elements were retained for this material. To predict potential damage of GFRP skins and GFRP connectors, specifically in the post-peak phase, the Hashin model [17, 20] was used to model the GFRP failure. The GFRP material parameters are presented in Table 3 and Table 7. The retained values were those of material characterisation and epoxy matrix strength. The GFRP materials were modelled with continuum shell elements. The mechanical polyurethane foam contribution was neglected and the foam was not modelled. A convergence study permitted to retain elements' size of $5 \times 5 \times 1 \mathrm{~mm}$ for the mineral layers, $5 \times 5$ $\mathrm{mm}$ for the GFRP skins and approximatively $0.4 \times 0.4 \times 0.7$ $\mathrm{mm}$ for the GFRP connectors. An implicit scheme was chosen, and the Newton-Raphson method was used for the equations' resolution. An automatic time incrementation was adopted with an initial increment size of 0.02 and a maximum one of 0.1 . To reduce the number of nodes and calculation tin, a half specimen was modelled and symmetric conditions were applied at midspan.

The mineral-GFRP interface was modelled using surface-based cohesive behaviour [17]. Contrary to cohesive elements, the named model doesn't assign material properties but interaction properties. Therefore, the interface thickness can be defined as nil, as is the case in the presented simulation. The linear behaviour is governed by equation 1 , where vectors $t$ and $\delta$ are respectively the nominal traction vector and the separation vector. $K$ is the interaction stiffness matrix. The traction-separation behaviour was setting uncoupled. Therefore, the stiffness variables $K_{n s}, K_{n t}$ and $K_{s t}$ were nil. The normal stiffness $K_{n n}$ was equal to the mineral material elastic modulus (15700 $\mathrm{MPa})$, and the shear stiffness $K_{s s}$ and $K_{t t}$ were equal to the mineral material shear modulus (5947 MPa).

Table 6. CDP model parameters.

\begin{tabular}{llll}
\hline Dilation angle & Eccentricity & $\mathrm{f}_{\mathrm{b} 0} / \mathrm{f}_{\mathrm{c} 0}$ & $\mathrm{~K}$ \\
\hline 34 & 0.1 & 1.16 & 0.667 \\
\hline
\end{tabular}

Table 7. Hashin model parameters.

\begin{tabular}{|c|c|c|c|c|}
\hline \multicolumn{5}{|c|}{ GFRP connectors } \\
\hline $\begin{array}{l}\text { Longitudinal } \\
\text { tensile }\end{array}$ & $\begin{array}{l}\text { Longitudinal } \\
\text { compression }\end{array}$ & $\begin{array}{l}\text { Transversal } \\
\text { tensile }\end{array}$ & $\begin{array}{l}\text { Transversal } \\
\text { compression }\end{array}$ & Shear \\
\hline $\begin{array}{l}X^{T}=18.4 \\
\mathrm{MPa}\end{array}$ & $X^{C}=70 \mathrm{MPa}$ & $Y^{T}=70 \mathrm{MPa}$ & $Y^{C}=70 \mathrm{MPa}$ & $\begin{array}{l}S=14 \\
\mathrm{MPa}\end{array}$ \\
\hline $\begin{array}{l}G_{f t}^{c}=0.14 \\
\mathrm{~N} / \mathrm{mm}\end{array}$ & $\begin{array}{l}G_{f c}^{c}=1.18 \\
\mathrm{~N} / \mathrm{mm}\end{array}$ & $\begin{array}{l}G_{m t}^{c}=1.24 \\
\mathrm{~N} / \mathrm{mm}\end{array}$ & $\begin{array}{l}G_{m c}^{c}=1.24 \\
\mathrm{~N} / \mathrm{mm}\end{array}$ & I \\
\hline \multicolumn{5}{|c|}{ GFRP skins } \\
\hline $\begin{array}{l}\text { Longitudinal } \\
\text { tensile }\end{array}$ & $\begin{array}{l}\text { Longitudinal } \\
\text { compression }\end{array}$ & $\begin{array}{l}\text { Transversal } \\
\text { tensile }\end{array}$ & $\begin{array}{l}\text { Transversal } \\
\text { compression }\end{array}$ & Shear \\
\hline $\begin{array}{l}X^{T}=137.8 \\
\mathrm{MPa}\end{array}$ & $X^{C}=70 \mathrm{MPa}$ & $X^{T}=70 \mathrm{MPa}$ & $Y^{C}=70 \mathrm{MPa}$ & $\begin{array}{l}S=14 \\
\mathrm{MPa}\end{array}$ \\
\hline $\begin{array}{l}G_{f t}^{c}=4.70 \\
\mathrm{~N} / \mathrm{mm}\end{array}$ & $\begin{array}{l}G_{f c}^{c}=1.20 \\
\mathrm{~N} / \mathrm{mm}\end{array}$ & $\begin{array}{l}G_{m t}^{c}=1.43 \\
\mathrm{~N} / \mathrm{mm}\end{array}$ & $\begin{array}{l}G_{m c}^{c}=1.43 \\
\mathrm{~N} / \mathrm{mm}\end{array}$ & I \\
\hline
\end{tabular}

$$
\left\{\begin{array}{l}
t_{n} \\
t_{s} \\
t_{t}
\end{array}\right\}=\left[\begin{array}{lll}
K_{n n} & K_{n s} & K_{n t} \\
K_{n s} & K_{s s} & K_{s t} \\
K_{n t} & K_{s t} & K_{t t}
\end{array}\right]\left\{\begin{array}{l}
\delta_{n} \\
\delta_{s} \\
\delta_{t}
\end{array}\right\}
$$

The damage initiates when a stress value of $t^{0}$ is reached. The implemented values were those presented in Fig. 7 and Fig. 9. The chosen post-peak behaviour was linear (cf. Fig. 12). The final separation $\delta^{f}$ was setting as $1.1 \times \delta^{0}$. Mixed mode parameters were calculated according to equation 2. $G_{T}^{c}$ is the total dissipated energy defined as the addition of $G_{n}^{c}, G_{s}^{c}$ and $G_{t}^{c}$.

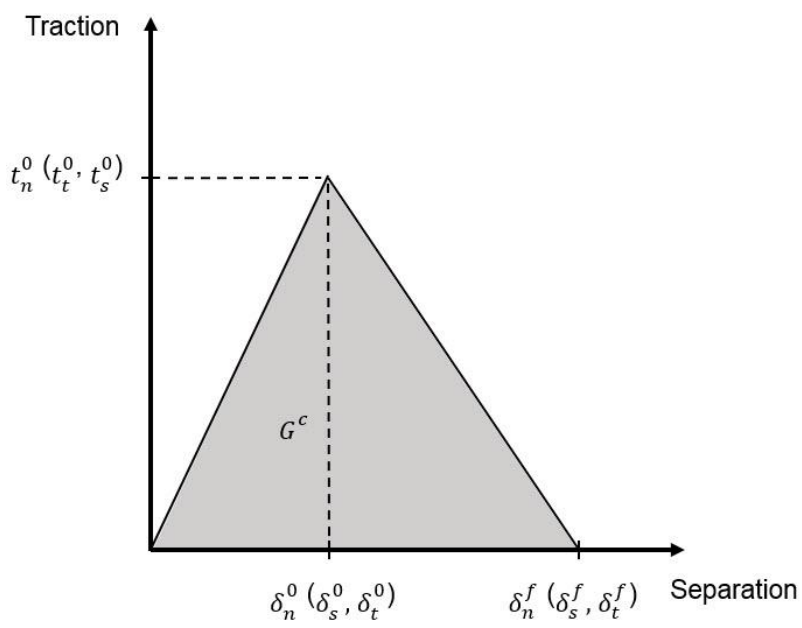

Fig. 12. Interface traction-separation low. 


$$
m_{1}=\frac{G_{n}^{c}}{G_{T}^{c}} \quad ; \quad m_{2}=\frac{G_{s}^{c}}{G_{T}^{c}}
$$

The FE responses are presented with experimental data in Fig. 13. The results exhibited good agreement in terms of stiffness, maximum force, and post-peak behaviour. The failure modes were reproduced. Fig. 14 illustrated the prediction of the interface failure by the FE model, in configuration (a).

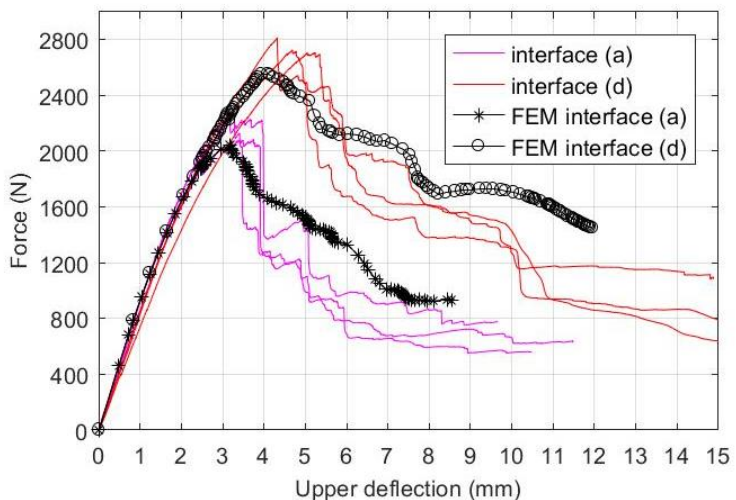

Fig. 13. Comparison of FE responses with experimental data.

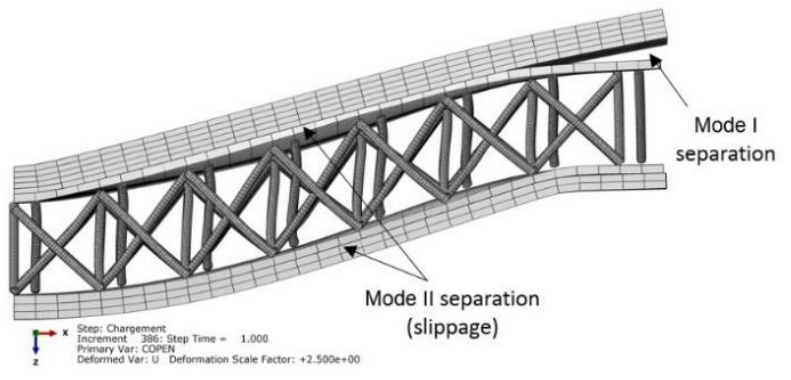

Fig. 14. FE interface failure of interface (a).

\section{Building applications}

In this section, the use of the presented sandwich panel in building refurbishment was assessed through a façade panel application and a lightweight floor panel use. On one side, several new thermal regulations in Europe (RT 2012 in France for instance) enforce the refurbishment of old buildings and the application of external thermal insulation to fit the new thermal requirements. In the case of cladding, façade panels with high mechanical properties can reduce the number of stud frame, decrease the application time and the solution's cost. On another note, sandwich panels can be very useful for damaged wood floor refurbishment. In numerous cases of buildings rehabilitation, heavy equipment can face access issues and lightweight pre-slab panels may be the appropriate solution. Furthermore, such panels avoid the addition of significant load to the existing structure. In what follows, the presented sandwich panel was designed for these two applications.

\subsection{Façade panels}

Two panels of $120 \mathrm{~cm}$ length and $60 \mathrm{~cm}$ were tested under distributed load (cf. Fig. 15). The section presented in Table 1 with interface (d) was retained for this use. The panel's mass density was $22.9 \mathrm{~kg} / \mathrm{m}^{2}$. The test was conducted by load increment and a $2 \mathrm{~Hz}$ data acquisition frequency was selected.

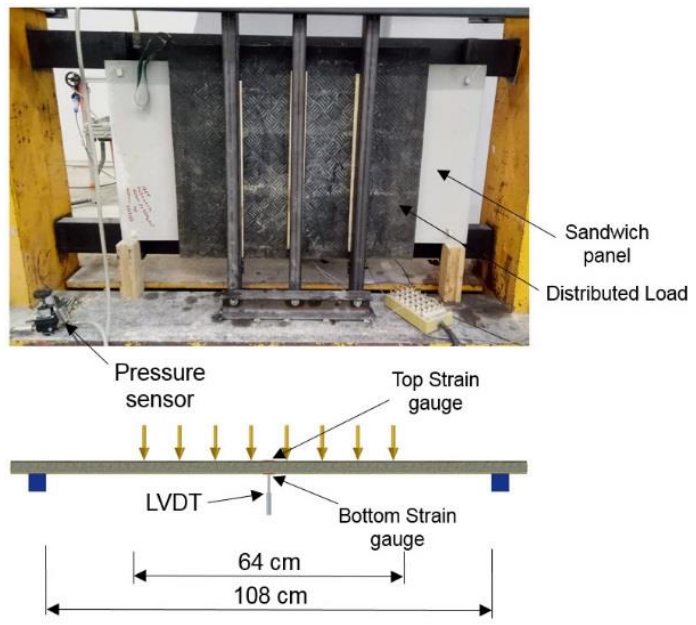

Fig. 15. Full-scale panel test for cladding use.

Thanks to the previously presented FE model, this test was simulated. The comparison between the model and the experimental responses is presented in Fig. 16 and Fig. 17. The FE responses fitted the experimental in terms of global and local behaviour. Regarding the French reVETIR standard [21], the requirements of the $V_{3}$ class were respected since no damage was observed before $1600 \mathrm{~Pa}$. A multi-cracking phase that led to the presented bilinear curve (cf. Fig. 16) initiated around a pressure of $2600 \mathrm{~Pa}$. No mineral layer delamination was experimentally observed. The FE simulation permitted shear stress assessment. Fig. 18 presented the shear distribution at a span of $8 \mathrm{~cm}$ for pressure of $1600 \mathrm{~Pa}$. The interface stress in the bottom skin was $0.12 \mathrm{MPa}$ (calculated as the difference of stress values in the mineral and GFRP layers). In accordance with the experimental observations, this value was lower than the mode II interface strength (cf. Fig. 9).

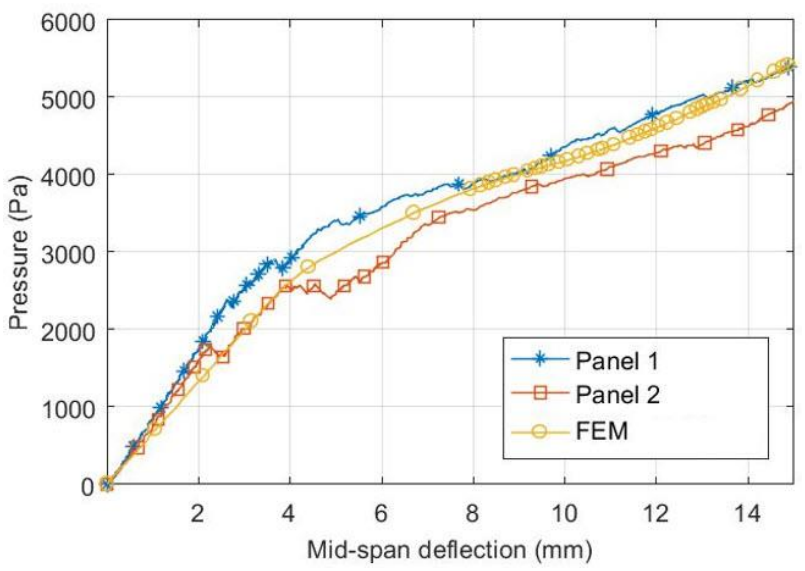

Fig. 16. Load-deflection curve of full-scale panel test: comparison of experimental and FE responses. 


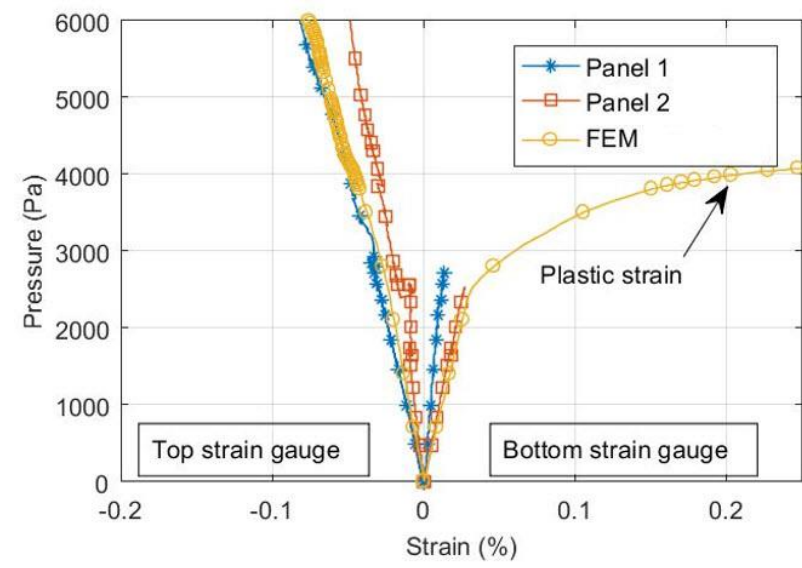

Fig. 17. Experimental and FE strain responses of full-scale panel test.

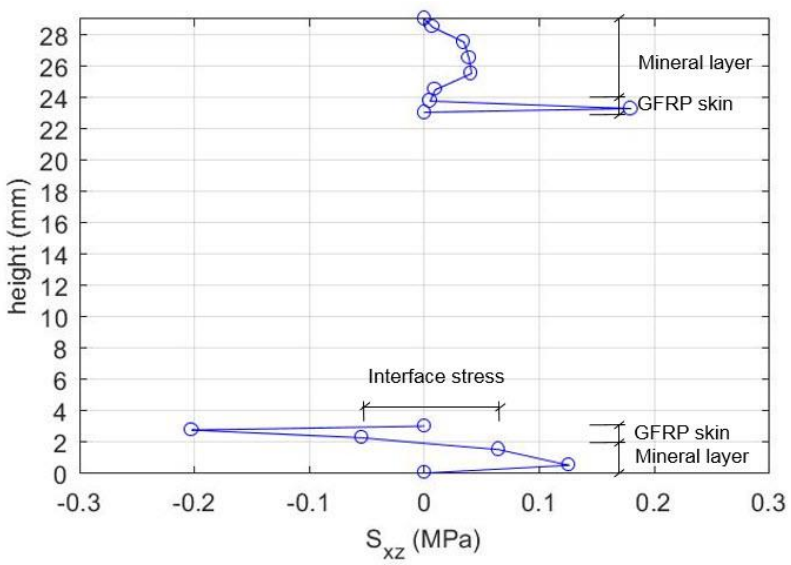

Fig. 18. Shear stress distribution at $x=8 \mathrm{~cm}$ and interface stress estimation.

\subsection{Pre-slab panels}

Panels of $250 \mathrm{~cm}$ length and $100 \mathrm{~cm}$ width were designed for a pre-slab panel application. The case study is presented in Fig. 19. An operating load of $150 \mathrm{~kg} / \mathrm{m}^{2}$ and a permanent load of $100 \mathrm{~kg} / \mathrm{m}^{2}$ were retained for the design. The permanent load was calculated as the weight addition of dead load $\left(25 \mathrm{~kg} / \mathrm{m}^{2}\right)$, floor covering (20 $\left.\mathrm{kg} / \mathrm{m}^{2}\right)$, plaster partitions $\left(40 \mathrm{~kg} / \mathrm{m}^{2}\right)$, and ceiling panels $\left(15 \mathrm{~kg} / \mathrm{m}^{2}\right)$.

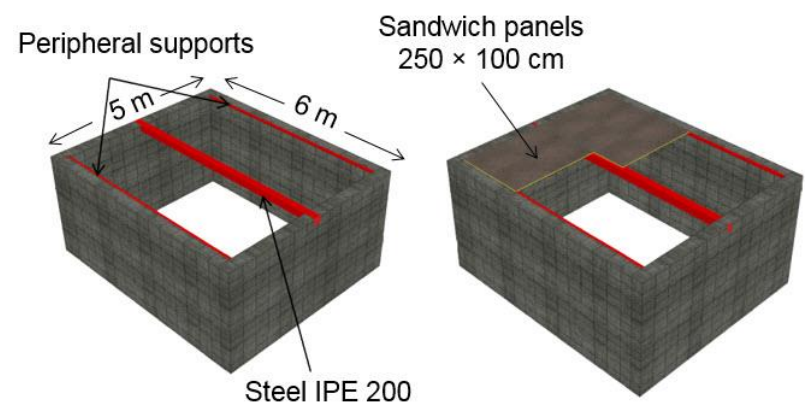

Fig. 19. Concept mapping for pre-slab use.

The FE design led to a section with a skin spacing $\left(S_{s k}\right)$ of $80 \mathrm{~mm}$, and a top mineral layer thickness $\left(t_{m-t}\right)$ of 8 $\mathrm{mm}$. No bottom mineral layer was retained to avoid premature cracks (fire issues should be fixed with appropriate insulation).

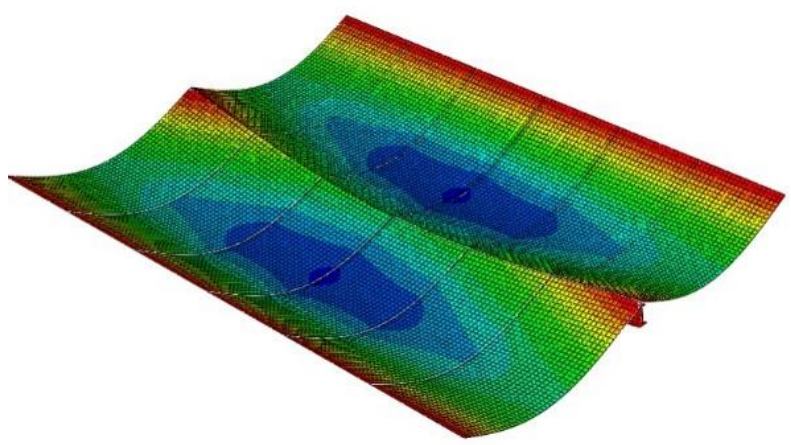

Fig. 20. Deflection shape of the presented pre-slab example.

The deflection shape presented in Fig. 20 highlighted the critical section in terms of deflection criterion. The deflection response was then assessed at this point and compared to a deflection criterion L/250. Fig. 21 indicated that the criterion was verified regarding the limit state of serviceability. Stress analysis showed that the stress distribution among the section and the mineral-GFRP interface was not detrimental.

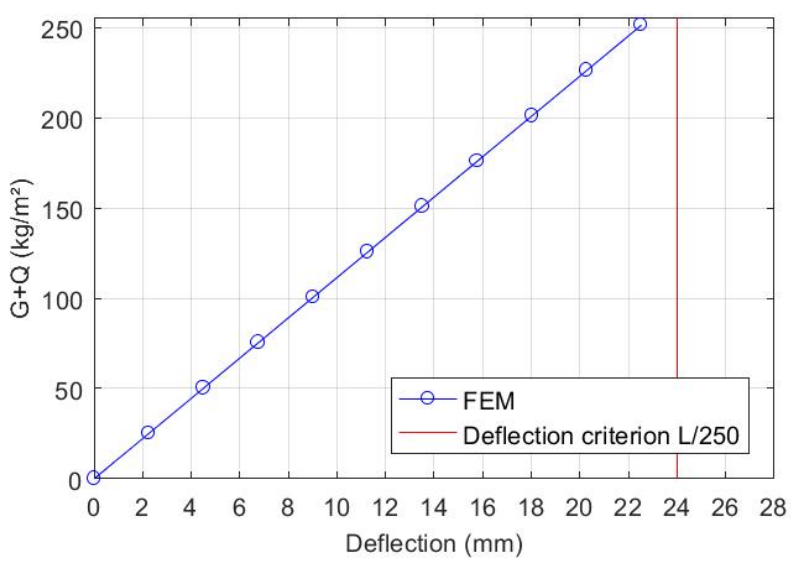

Fig. 21. Deflection response of the critical section of the presented pre-slab example.

\section{Conclusions}

The presented manufacturing process led to highperformance sandwich panels by resolving the shear deflection issues thanks to GFRP connectors. The interface strength was assessed through tensile and pushout test. The results of the different tested configurations indicated that the addition of an interleaf sand layer at the mineral-GFRP interface increased 3.8 times the mode I strength and 1.7 times the mode II strength. The presented FE model reproduced the sandwich panel mechanical behaviour, including interface failures thanks to surfacebased cohesive analysis. Designs for façade cladding and pre-slab uses were presented. The analysis showed that the responses fulfilled criteria in terms of stresses and deflection. The mass density of the panels (less than 25 $\mathrm{kg} / \mathrm{m}^{2}$ ) allows easy and quick fastening. Since the preslabs are intended for structural use, additional analysis should be performed regarding dynamic loads and fatigue. 


\section{References}

[1] J. R. Vinson, Springer Dordrecht, Sandwich Structures: Past, Present, and Future, 3-12, (2005)

[2] V. Birman and G. A. Kardomateas, Compos B Eng, Review of current trends in research and applications of sandwich structures, 142, 221-240, (2018).

[3] J. Chróścielewski, M. Miśkiewicz, Ł. Pyrzowski, B. Sobczyk, and K. Wilde, Compos B Eng, A novel sandwich footbridge-Practical application of laminated composites in bridge design and in situ measurements of static response, 126, 153-161, (2017).

[4] P. M. Hopkins, T. Norris, and A. Chen, Compos. Struct., Creep behavior of insulated concrete sandwich panels with fiber-reinforced polymer shear connectors, 172, 137146, (2017)

[5] T. Sharaf and A. Fam, Thin-Walled Struct., Analysis of large scale cladding sandwich panels composed of GFRP skins and ribs and polyurethane foam core, 71, 91-101, (2013)

[6] C. Pascual, J. Montali, and M. Overend, Compos. Struct, Adhesively-bonded GFRP-glass sandwich components for structurally efficient glazing applications, 160, 560-573, (2017).

[7] N. Williams Portal, M. Flansbjer, K. Zandi, L. Wlasak, and K. Malaga, Compos. Struct, Bending behaviour of novel Textile Reinforced Concrete-foamed concrete (TRCFC) sandwich elements, 177, 104-118, (2017)

[8] R. Lameiras, J. Barros, I. B. Valente, and M. Azenha, Compos. Struct, Development of sandwich panels combining fibre reinforced concrete layers and fibre reinforced polymer connectors. Part I: Conception and pull-out tests, 105, 446-459, (2013)

[9] M. Mastali, I. B. Valente, and J. A. O. Barros, Compos. Struct, Flexural performance of innovative hybrid sandwich panels with special focus on the shear connection behavior, 160, 100-117, (2017)

[10] S. Daynes, S. Feih, W. F. Lu, and J. Wei, Mater Design, Optimisation of functionally graded lattice structures using isostatic lines, 127, 215-223, (2017)

[11] I. Ullah, J. Elambasseril, M. Brandt, and S. Feih, Compos. Struct, Performance of bio-inspired Kagome truss core structures under compression and shear loading, 118, 294-302, (2014)

[12] J. Mei, J. Liu, and J. Liu, Compos A Appl Sci Manuf, $A$ novel fabrication method and mechanical behavior of allcomposite tetrahedral truss core sandwich panel, 102, 2839, (2017)

[13] N. Mitra, A. Patra, S. Mondal, and P. K. Datta, Eng. Struct, Interfacial delamination crack profile estimation in polymer foam-cored sandwich composites, 189, 635-643, (2019)

[14] K. Djama, L. Michel, A. Gabor, and E. Ferrier, Compos. Struct, Mechanical behaviour of a sandwich panel composed of hybrid skins and novel glass fibre reinforced polymer truss core, 215, 35-48, (2019)

[15] M. Pietrek and P. Horst, Compos. Struct, Analysis and numerical prediction of the delamination behavior of debonded asymmetric sandwich shells with a thin-walled skin considering plastic deformation, 188, 220-232, (2018)

[16] Core material for composites: SAERfoam ${ }^{\circledR}$, [Online], Available: http://www.saertex.com/en/products/saerfoam, (Accessed: 09-Mar-2018)
[17] Abaqus Analysis User's Guide (6.14), [Online], Available: https://www.sharcnet.ca/Software/Abaqus/6.14.2/v6.14/b ooks/usb/default.htm, (Accessed: 25-Jan-2019)

[18] T. Brockmann, Mechanical and fracture mechanical properties of fine-grained concrete for textile reinforced composites, Mainz, Aachen, (2006)

[19] J. LUBLINER, J. OLIVER, S. OLLER, and E. ONATE, Int J Solids Struct, A plastic-damage model for concrete, 25, 299-329, (1989)

[20] Z. Hashin, J. Appl. Mech, Failure Criteria for Unidirectional Fiber Composites, 47, 329-334, (1980)

[21] CSTB, Classement reVETIR des systèmes d'isolation thermique des façades par l'extérieur, (1996) 